\title{
Control of Chenopodium album L. and Echinochloa crus-galli L. in non-GMO soybean (Glycine max L.)
}

\author{
Ochrona konwencjonalnych odmian soi (Glycine max L.) \\ przed zachwaszczeniem komosą białą (Chenopodium album L.) \\ i chwastnicą jednostronną (Echinochloa crus-galli L.)
}

\author{
Adrian Luboiński*
}

\section{Summary}

The aim of the field experiments was to evaluate the efficacy of some pre-emergence herbicides applied in a soybean crop; variety Augusta. The field experiments were conducted during the years 2014-2016 in the Field Experimental Station at Winna Góra using randomized complete blocks design with four replications. The data collected and analyzed from these experiments allowed to select the herbicides that showed high weed control efficacy of most harmful weed species such as Chenopodium album L. and Echinochloa crus-galli L. and also proved to be safe for the crop. The most effective combination of herbicides were: linuron + clomazone, linuron + S-metolachlor and flufenacet + metribuzin. These combinations were characterized by high efficacy during favorable weather conditions.

Key words: non-GMO soybean; soil applied herbicides; weed infestation

\section{Streszczenie}

Celem przeprowadzonych doświadczeń polowych była ocena skuteczności działania herbicydów stosowanych doglebowo w uprawie soi odmiany Augusta. Doświadczenia polowe przeprowadzono w latach 2014-2016 w Polowej Stacji Doświadczalnej w Winnej Górze, w układzie bloków losowanych kompletnych, w czterech powtórzeniach. Po dwóch latach badań wytypowano herbicydy, które charakteryzowały się wysoką skutecznością zwalczania najbardziej szkodliwych chwastów w uprawie soi, tj.: komosy białej (Chenopodium album L.) i chwastnicy jednostronnej (Echinochloa crus-galli L.), a jednocześnie były selektywne dla rośliny uprawnej. Najskuteczniejszymi kombinacjami herbicydowymi były: linuron + chlomazon, linuron + S-metolachlor oraz flufenacet + metrybuzyna. Kombinacje te wykazały wysoką skuteczność działania podczas sprzyjających warunków atmosferycznych.

Słowa kluczowe: soja konwencjonalna; herbicydy doglebowe; zachwaszczenie 


\section{Wstęp / Introduction}

Powierzchnia uprawy soi w świecie wynosi ponad 100 milionów hektarów, a 90\% tego areału znajduje się w pięciu państwach: Argentyna, Brazylia, USA, Chiny, Indie (Vivian i wsp. 2013). W państwach tych uprawiane są głównie odmiany soi genetycznie modyfikowane (GMO - Genetically Modified Organism) w kierunku odporności na substancję czynną - glifosat. Możliwość użycia tego herbicydu znacznie uprościła ochronę plantacji przed chwastami i obniżyła koszty zabiegów (Tyczewska i wsp. 2014). Z uwagi na zastrzeżenia i wątpliwości w stosunku do roślin genetycznie modyfikowanych, w licznych krajach europejskich, w tym w Polsce, uprawa tych roślin jest prawnie zakazana. Na rynku soi obserwuje się coraz większe zapotrzebowanie na nasiona konwencjonalnych odmian, które stanowią obecnie tylko około $10 \%$ globalnego handlu tym surowcem (Tyczewska i wsp. 2014). Wyhodowanie konwencjonalnych odmian soi o krótkim okresie wegetacji umożliwiło jej uprawę także w warunkach klimatycznych Polski (Kapusta 2012).

We wszystkich rejonach uprawy soi w świecie największy problem stanowi ochrona plantacji przed zachwaszczeniem, w związku z tym konieczne jest użycie herbicydów. Soja jest rośliną charakteryzującą się wolnym tempem wzrostu, dlatego w początkowych fazach rozwojowych łatwo ulega zachwaszczeniu (Jędruszczak i wsp. 2010). Problemem są głównie zbiorowiska chwastów jarych, a w mniejszym stopniu gatunki wieloletnie (Korsak-Adamowicz i wsp. 2010). W celu ochrony plantacji przed chwastami powszechnie stosowane są herbicydy doglebowe (Jędruszczak i wsp. 2010). Dla ochrony konwencjonalnych odmian soi w USA zalecane są liczne substancje czynne będące składnikami herbicydów doglebowych, między innymi: acetochlor, chlorimuron, chlomazon, chloransulam, dimetenamid-P, flumetsulam, flumioksazyna, fomesafen, glifosat, imazakwin, imazetapyr, linuron, metrybuzyna, pendimetalina, pyroksasulfon, saflufenacyl, S-metolachlor, sulfentrazon, tifensulfuron, tribenuron oraz trifluralina (Loux i wsp. 2015). Aktualnie w Polsce dopuszczone do ochrony soi są następujące herbicydy: Afalon Dyspersyjny 450 SC (linuron), Boxer 800 EC (prosulfokarb), Corum 502,4 SL (bentazon, imazamoks), Dual Gold 960 EC (S-metolachlor), Focus Ultra 100 EC (cykloksydym), Fusilade Forte 150 EC (fluazyfop-P butylu), Plateen 41,5 WG (flufenacet, metrybuzyna), Proman 500 SC (metobromuron), Sencor Liquid 600 SC (metrybuzyna), Stomp Aqua 455 CS (pendimetalina) oraz Trivko (fluazyfop-P butylu).

Celem przeprowadzonych badań była ocena skuteczności zwalczania komosy białej (Chenopodium album L.) i chwastnicy jednostronnej (Echinochloa crus-galli L.) oraz ocena fitotoksycznego oddziaływania herbicydów i ich mieszanin stosowanych doglebowo, zawierających chlomazon, flufenacet, linuron, metrybuzynę, pendimetalinę, petoksamid, S-metolachlor oraz terbutylazynę, w uprawie konwencjonalnej odmiany soi. Założono, że zastosowanie odpowiednich mieszanin herbicydów doglebowych będzie skutecznie chronić uprawę soi przed zachwaszczeniem komosą biała i chwastnicą jednostronną.

\section{Materiały i metody / Materials and methods}

Badania przeprowadzono w latach 2014-2016 w Polowej Stacji Doświadczalnej w Winnej Górze, w uprawie soi odmiany Augusta. Poletka o powierzchni $22 \mathrm{~m}^{2}$ zlokalizowane były na glebie ornej dobrej (glina piaszczysta, klasa bonitacyjna - IIIa), której odczyn wynosił 4,7-5,0 pH, a zawartość substancji organicznej w glebie: 1,04-1,19\%. Doświadczenia założono w układzie bloków losowanych kompletnych, w czterech powtórzeniach. Soję wysiewano w ostatniej dekadzie kwietnia w ilości $120 \mathrm{~kg} / \mathrm{ha}$, w obsadzie 80 roślin na $\mathrm{m}^{2}$, a rozstaw rzędów wynosił $25 \mathrm{~cm}$. Nasiona zaprawiono szczepionką bakteryjną zawierającą szczepy bakterii Bradyrhizobium japonicum. Przedplonami były kolejno: kukurydza (2014), rzepak ozimy (2015) oraz pszenica jara (2016). Po siewie wykonano zabiegi różnymi kombinacjami herbicydów doglebowych. Nasiona zebrano

Tabela 1. Skuteczność zwalczania chwastów w latach 2014-2016

Table 1. Weed control efficiency in 2014-2016

\begin{tabular}{|c|c|c|c|c|c|c|c|}
\hline \multirow{3}{*}{$\begin{array}{c}\text { Obiekty } \\
\text { Treatments }\end{array}$} & \multirow{3}{*}{$\begin{array}{l}\text { Dawka } \\
\text { Dose } \\
\text { [g/ha] }\end{array}$} & \multicolumn{6}{|c|}{ Skuteczność zwalczania chwastów - Weed control efficiency [\%] } \\
\hline & & \multicolumn{2}{|c|}{2014} & \multicolumn{2}{|c|}{2015} & \multicolumn{2}{|c|}{2016} \\
\hline & & CHEAL & ECHCG & CHEAL & ECHCG & CHEAL & ECHCG \\
\hline Linuron + clomazone & $1000+72$ & $100 \mathrm{a}$ & $100 \mathrm{a}$ & 79 a & $55 \mathrm{a}$ & 98 a & $74 \mathrm{c}$ \\
\hline Linuron + S-metolachlor & $1000+960$ & $100 \mathrm{a}$ & $100 \mathrm{a}$ & $80 \mathrm{a}$ & 53 a & $100 \mathrm{a}$ & $100 \mathrm{a}$ \\
\hline Linuron & 1000 & $100 \mathrm{a}$ & $84 \mathrm{~b}$ & $75 \mathrm{a}$ & $0 \mathrm{~d}$ & $81 \mathrm{c}$ & $80 \mathrm{c}$ \\
\hline Pendimethalin + clomazone & $1592,5+72$ & $100 \mathrm{a}$ & $99 \mathrm{a}$ & $78 \mathrm{a}$ & $25 \mathrm{bc}$ & $90 \mathrm{~b}$ & $90 \mathrm{~b}$ \\
\hline Pendimethalin & 1820 & $100 \mathrm{a}$ & $99 \mathrm{a}$ & 79 a & $28 \mathrm{~b}$ & $97 \mathrm{a}$ & $65 \mathrm{~d}$ \\
\hline Pethoxamid + terbuthylazine & $1200+1000$ & $90 \mathrm{~b}$ & $87 \mathrm{~b}$ & $83 \mathrm{a}$ & $5 \mathrm{~cd}$ & 99 a & $97 \mathrm{ab}$ \\
\hline Flufenacet + metribuzin & $480+350$ & $100 \mathrm{a}$ & $100 \mathrm{a}$ & $83 \mathrm{a}$ & $30 \mathrm{~b}$ & $100 \mathrm{a}$ & $98 \mathrm{ab}$ \\
\hline
\end{tabular}

CHEAL - Chenopodium album, ECHCG - Echinochloa crus-galli

Średnia liczba chwastów $/ \mathrm{m}^{2}$ na kontroli - Average number of weeds in a control plot:

2014: CHEAL - 75, ECHCG - 17; 2015: CHEAL - 55, ECHCG - 8; 2016: CHEAL - 10, ECHCG - 16

Wartości w kolumnach oznaczone tą samą litera nie różnią się istotnie przy $p=0,05$

Values in columns followed by the same letter do not differ significantly at $\mathrm{p}=0.05$ 
Tabela 2. Uszkodzenia roślin soi przez herbicydy w latach 2014-2016

Table 2. Soybean injury by herbicides in 2014-2016

\begin{tabular}{|c|c|c|c|c|c|c|c|c|c|c|c|c|c|}
\hline \multirow{4}{*}{$\begin{array}{c}\text { Obiekty } \\
\text { Treatments }\end{array}$} & \multirow{4}{*}{$\begin{array}{c}\text { Dawka } \\
\text { Dose } \\
\text { [g/ha] }\end{array}$} & \multicolumn{12}{|c|}{ Stadium rozwojowe soi - Growth stage of soybean $(\mathrm{BBCH})$} \\
\hline & & 10 & 13 & 49 & 97 & 10 & 13 & 49 & 97 & 10 & 13 & 49 & 97 \\
\hline & & \multicolumn{4}{|c|}{2014} & \multicolumn{4}{|c|}{2015} & \multicolumn{4}{|c|}{2016} \\
\hline & & \multicolumn{12}{|c|}{ uszkodzenia roślin - plant injury [\%] } \\
\hline Linuron + clomazone & $1000+72$ & 0 & 0 & 0 & 0 & 0 & 0 & 0 & 0 & 0 & 0 & 0 & 0 \\
\hline Linuron + S-metolachlor & $1000+960$ & 0 & 0 & 0 & 0 & 0 & 0 & 0 & 0 & 0 & 0 & 0 & 0 \\
\hline Linuron & 1000 & 0 & 0 & 0 & 0 & 0 & 0 & 0 & 0 & 0 & 0 & 0 & 0 \\
\hline Pendimethalin + clomazone & $1592,5+72$ & 0,5 & 2,3 & 13,3 & 9 & 0 & 0 & 0 & 0 & 0 & 0 & 0 & 0 \\
\hline Pendimethalin & 1820 & 0,3 & 1,8 & 13,3 & 7,3 & 0 & 0 & 0 & 0 & 0 & 0 & 0 & 0 \\
\hline Pethoxamid + terbuthylazine & $1200+1000$ & 0,3 & 0,8 & 0 & 0 & 0 & 0 & 0 & 0 & 4 & 3 & 0 & 0 \\
\hline Flufenacet + metribuzin & $480+350$ & 0 & 1 & 0 & 0 & 0 & 0 & 0 & 0 & 0 & 0 & 0 & 0 \\
\hline
\end{tabular}

kombajnem poletkowym Wintersteiger Classic, następnie określono wysokość plonu. Przedmiotem badań były herbicydy stosowane doglebowo, bezpośrednio po siewie soi: linuron (Linurex $500 \mathrm{SC}$ ), linuron + chlomazon (Linurex 500 SC + Command 480 EC), linuron + S-metolachlor (Linurex 500 SC + Dual Gold 960 EC), pendimetalina (Stomp Aqua $455 \mathrm{CS}$ ), pendimetalina + chlomazon (Stomp Aqua 455 CS + Command 480 EC), petoksamid + terbutylazyna (Successor T 550 SE), flufenacet + metrybuzyna (Plateen 41,5 WG). Zabiegi wykonano za pomocą plecakowego opryskiwacza wyposażonego w cztery rozpylacze Tee Jet AXR 110/03. Ciśnienie cieczy roboczej $\mathrm{W}$ rozpylaczu wynosiło $0,2 \mathrm{MPa}$, prędkość w trakcie zabiegu wynosiła $5,0 \mathrm{~km} / \mathrm{h}$, a wydatek cieczy roboczej w przeliczeniu na 1 ha wynosił 2001.

Oceny skuteczności działania herbicydów oraz oceny fitotoksycznego działania herbicydów na rośliny soi wykonano metodą wizualną. Oceny skuteczności wykonano w fazach rozwojowych: 13, 49, 97 według skali $\mathrm{BBCH}$, natomiast oceny fitotoksyczności wykonano w fazach rozwojowych: 10, 13, 49, 97 według skali $\mathrm{BBCH}$. Na poletkach kontrolnych określono liczbę roślin komosy białej oraz chwastnicy jednostronnej. Wyniki skuteczności przedstawiono w skali procentowej, gdzie 100\% oznacza całkowite zniszczenie chwastu, natomiast $0 \%$ oznacza brak działania herbicydu. W ocenie fitotoksyczności ocena $100 \%$ oznacza całkowite zniszczenie roślin soi, a $0 \%$ brak fitotoksycznego działania herbicydu na roślinę uprawną. Wyniki skuteczności uzyskane w poszczególnych sezonach wegetacyjnych przedstawiono jako średnią z trzech ocen (tab. 1). Wyniki fitotoksyczności przedstawiono osobno dla poszczególnych sezonów wegetacyjnych (tab. 2). Uzyskane wyniki skuteczności chwastobójczej oraz wysokość plonu poddano analizie wariancji (ANOVA) wykorzystując program komputerowy ARM (wersja 9) firmy Gylling Data Management, Inc. Aby określić istotne różnice pomiędzy średnimi z ocen zastosowano test Tukeya na poziomie istotności $\alpha=0,05$.

\section{Wyniki i dyskusja / Results and discussion}

Wyniki skuteczności chwastobójczej z trzech sezonów wskazują, iż linuron i chlomazon zastosowane łącznie w dawkach $1000 \mathrm{~g} / \mathrm{ha}+72 \mathrm{~g} /$ ha charakteryzowały się bardzo wysoką skutecznością zwalczania komosy białej w latach 2014 i 2016, która wyniosła odpowiednio 100\% i $98 \%$ oraz skutecznością na poziomie $79 \%$ w sezonie 2015. Skuteczność zwalczania chwastnicy jednostronnej w kolejnych latach badań wynosiła $100 \%$, 55\% oraz $74 \%$. Niższe wyniki skuteczności odnotowano w sezonie 2015, których powodem było wystąpienie suszy w okresie wiosenno-letnim (rys. 1). Kombinacja ta była selektywna dla soi konwencjonalnej odmiany Augusta.

Mieszanina linuronu z S-metolachlorem w dawkach $1000 \mathrm{~g} / \mathrm{ha}+960 \mathrm{~g} / \mathrm{ha}$ charakteryzowała się najwyższą skutecznością zwalczania zarówno komosy białej, jak i chwastnicy jednostronnej. Skuteczność zwalczania komosy białej w latach 2014-2016 wyniosła odpowiednio $100 \%$, $80 \%$ oraz $100 \%$. Chwastnica jednostronna w kolejnych latach badań została zwalczona na poziomie $100 \%$, $53 \%$ oraz $100 \%$. Kombinacja nie powodowała uszkodzeń roślin soi. Bujak i Frant (2009) potwierdzili w swoich badaniach, iż połączenie linuronu z S-metolachlorem skutecznie ogranicza liczbę chwastów w łanie soi poprzez zmniejszenie dominującej roli chwastnicy jednostronnej.

Linuron w dawce $1000 \mathrm{~g} / \mathrm{ha}$ podczas trzech lat badań zwalczał komosę białą na poziomie $100 \%, 75 \%$ oraz $81 \%$. Preparat charakteryzował się dobrą skutecznością zwalczania chwastnicy jednostronnej w latach 2014 (84\%) oraz 2016 (80\%). Deficyt opadów w sezonie wegetacyjnym 2015 spowodował brak działania linuronu stosowanego osobno na rośliny chwastnicy jednostronnej $(0 \%)$. Herbicyd nie powodował uszkodzeń roślin uprawnej.

Mieszanina pendimetaliny z chlomazonem w dawkach odpowiednio $1592,5 \mathrm{~g} /$ ha i $72 \mathrm{~g} /$ ha charakteryzowała się wysoką skutecznością zwalczania komosy białej w latach $2014(100 \%)$ i $2016(90 \%)$ oraz skutecznością na poziomie 78\% w sezonie 2015. Kombinacja tych dwóch substancji czynnych charakteryzowała się wysoką skutecznością zwalczania chwastnicy jednostronnej w latach 2014 $(100 \%)$ i $2016(90 \%)$ oraz niską $(25 \%)$ w suchym roku 2015. Mieszanina pendimetaliny $\mathrm{z}$ chlomazonem $\mathrm{w}$ roku 2014 powodowała uszkodzenia soi odmiany Augusta (opóźnienie rozwoju, deformacje liści oraz zasychanie roślin), które osiągnęły wysokość około 13\% i utrzymywały się do końca sezonu wegetacyjnego. 


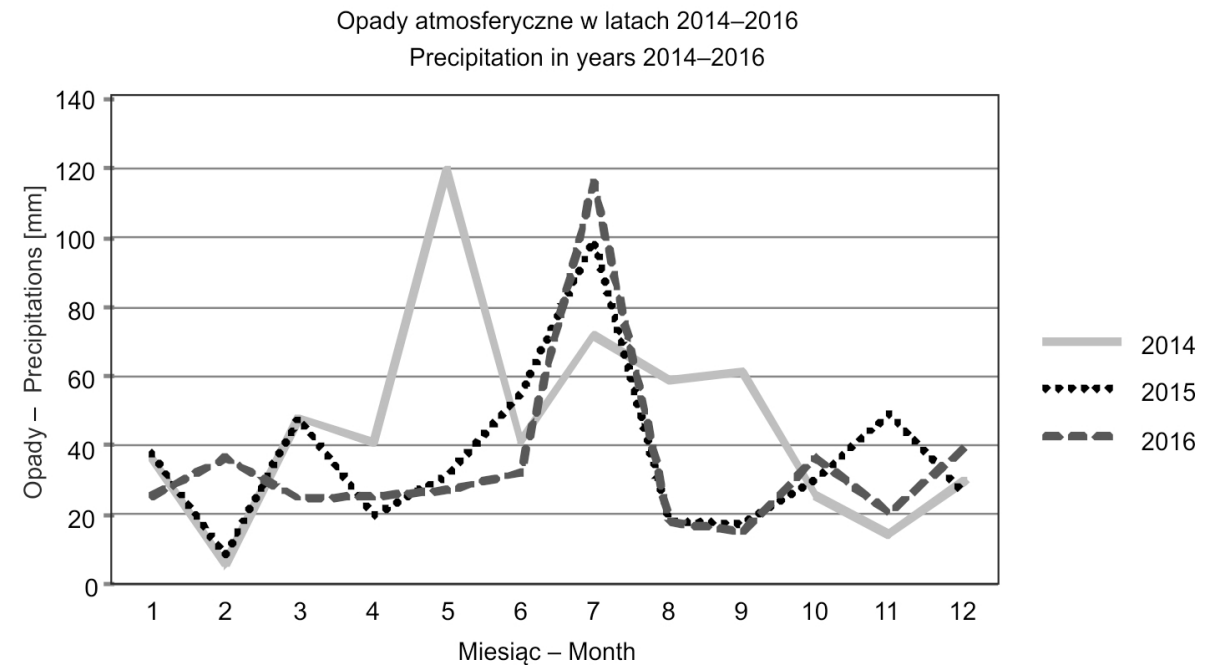

Suma opadów w roku 2014 - Sum of precipitation in year 2014: 555,3 mm

Suma opadów w roku 2015 - Sum of precipitation in year 2015: 443,5 mm

Suma opadów w roku 2016 - Sum of precipitation in year 2016: 418,9 mm

Suma opadów od kwietnia do września 2014 - Sum of precipitation from April to September 2014: 393,7 mm

Suma opadów od kwietnia do września 2015 - Sum of precipitation from April to September 2015: 242,8 mm

Suma opadów od kwietnia do września 2016 - Sum of precipitation from April to September 2016: 235,1 mm

Rys. 1. Opady atmosferyczne w latach 2014-2016

Fig. 1. Precipitation in years 2014-2016

Pendimetalina zastosowana w dawce 1820 g/ha charakteryzowała się wysoką skutecznością zwalczania komosy białej w latach 2014 i 2016, która wynosiła odpowiednio $100 \%$ i $97 \%$ oraz skutecznością na poziomie $79 \% \mathrm{w}$ sezonie 2015. Charakteryzowała się także wysoką skutecznością zwalczania chwastnicy jednostronnej w sezonie 2014 $99 \%$ przy niższej skuteczności zwalczania w latach 2015 i 2016 (odpowiednio 28\% i 65\%). Herbicyd w 2014 roku spowodował znaczne uszkodzenia soi (około 13\%), które utrzymywały się do końca sezonu wegetacyjnego (opóźnienie rozwoju, deformacje liści oraz zasychanie roślin). Younesabadi i wsp. (2013) w swoich badaniach wykazali, że skuteczność chwastobójcza pendimetaliny zastosowanej pojedynczo jest niewystarczająca. Według autorów stosowanie pendimetaliny łącznie $\mathrm{z}$ innymi herbicydami wpływa na wysokość skuteczności chwastobójczej. Za przykład podają mieszaninę z imazetapyrem, która charakteryzowała się bardzo wysoką skutecznością w porównaniu do pendimetaliny zastosowanej pojedynczo.

Petoksamid i terbutylazyna zastosowane w dawkach $1200 \mathrm{~g} / \mathrm{ha}+1000 \mathrm{~g} / \mathrm{ha}$ skutecznie zwalczały rośliny komosy białej, gdzie stopień zniszczenia roślin w kolejnych latach wynosił 90\%, 83\%, 99\%, a jednocześnie charakteryzowały się wysoką skutecznością zwalczania chwastnicy jednostronnej w latach 2014 (87\%) i 2016 (97\%) oraz bardzo niską skutecznością na poziomie 5\% w sezonie 2015. Niższa skuteczność spowodowana była warunkami suszy. Preparat w roku 2014 w niewielkim stopniu oddziaływał fitotoksycznie na soję odmiany Augusta (0,3-0,8\%), jednak uszkodzenia te miały charakter przemijający.

Flufenacet i metrybuzyna zastosowane w dawkach $480 \mathrm{~g} / \mathrm{ha}+350 \mathrm{~g} / \mathrm{ha}$ charakteryzowały się wysoką skutecz- nością zwalczania komosy białej podczas trzech lat badań - 100\%, 83\%, 100\%. Skuteczność zwalczania chwastnicy jednostronnej wynosiła w sezonie 2014 - 100\%, w sezonie 2015 - 30\%, w sezonie 2016 - 98\%. Preparat w sezonie 2014 w niewielkim stopniu uszkadzał rośliny soi (1\%), uszkodzenia zaobserwowano podczas drugiej oceny fitotoksyczności. Jak podaje Hamill i wsp. (1994) w Kanadzie metrybuzyna stosowana jest powszechnie do zwalczania jednorocznych chwastów w soi. Jednak niektóre odmiany soi są wrażliwe na ten herbicyd i wtedy należy stosować preparaty w dawkach obniżonych.

Wynikiem wysokiej skuteczności chwastobójczej wszystkich badanych preparatów był przyrost plonu w stosunku do obiektu kontrolnego. Najwyższy przyrost zaobserwowano na obiektach, na których zastosowano następujące substancje czynne: linuron + chlomazon, linuron + S-metolachlor, flufenacet + metrybuzyna. Ze względu na niską skuteczność spowodowaną warunkami suszy w sezonie 2015 plonu nie zebrano. Dane przedstawiono w tabeli 3.

W wyniku przeprowadzonych badań stwierdzono wpływ wysokości opadów atmosferycznych w sezonie wegetacji na skuteczność działania preparatów doglebowych. Badane preparaty aplikowane były na przełomie kwietnia i maja, natomiast soję zbierano we wrześniu. W roku 2014 suma opadów atmosferycznych od kwietnia do września wyniosła 393,70 mm, w roku 2015 - 242,80 $\mathrm{mm}$, natomiast $\mathrm{w}$ sezonie 2016 - 235,1 mm (rys. 1). Generalnie zaobserwowano wyższą skuteczność chwastobójczą testowanych preparatów w sezonie 2014 o większej ilości opadów w porównaniu do lat 2015 i 2016. Najniższe wyniki skuteczności chwastobójczej obserwowano w roku 2015, co spowodowane było brakiem okrywy śnieżnej 


\begin{tabular}{|c|c|c|c|}
\hline \multirow{2}{*}{$\begin{array}{c}\text { Obiekty } \\
\text { Treatments }\end{array}$} & \multirow{2}{*}{$\begin{array}{l}\text { Dawka } \\
\text { Dose } \\
\text { [g/ha] }\end{array}$} & \multicolumn{2}{|c|}{$\begin{array}{c}\text { Plon - Yield* } \\
\text { [t/ha] }\end{array}$} \\
\hline & & 2014 & 2016 \\
\hline Kontrola - Untreated & - & $0,48 \mathrm{c}$ & 0,39 e \\
\hline Linuron + clomazone & $1000+72$ & $2,56 \mathrm{ab}$ & $0,80 \mathrm{~b}$ \\
\hline Linuron + S-metolachlor & $1000+960$ & $2,25 \mathrm{ab}$ & $0,72 \mathrm{bc}$ \\
\hline Linuron & 1000 & $2,05 \mathrm{ab}$ & $0,61 \mathrm{~cd}$ \\
\hline Pendimethalin + clomazone & $1592,5+72$ & $1,40 \mathrm{bc}$ & 0,52 de \\
\hline Pendimethalin & 1820 & $1,31 \mathrm{bc}$ & $0,54 \mathrm{cde}$ \\
\hline Pethoxamid + terbuthylazine & $1200+1000$ & $1,96 \mathrm{ab}$ & $0,56 \mathrm{cde}$ \\
\hline Flufenacet + metribuzin & $480+350$ & 2,84 a & 1,05 a \\
\hline
\end{tabular}

${ }^{*}{ }_{\mathrm{w}} 2015$ roku plonu nie zebrano z powodu długotrwałej suszy - in 2015 soybean was not harvested due to the long period of drought

Wartości w kolumnach oznaczone tą samą literą nie różnią się istotnie przy p $=0,05$

Values in columns followed by the same letter do not differ significantly at $\mathrm{p}=0.05$

zimą w porównaniu do roku 2016 oraz bardzo niskimi opadami atmosferycznymi w kwietniu, czyli w okresie stosowania herbicydów doglebowych w soi. Suma opadów atmosferycznych w kwietniu w poszczególnych latach badań wynosiła: 2014 - 40,6 mm; 2015 - 20,1 mm; 2016 25,7 mm. Woźnica (2008) stwierdził, iż opady deszczu zazwyczaj korzystnie wpływają na aktywację oraz przemieszczanie herbicydów doglebowych w strefę kiełkowania nasion chwastów oraz ich absorpcję przez chwasty. Zdaniem Praczyka i Skrzypczaka (2004) stosowanie herbicydów doglebowych podczas suszy powoduje obniżenie skuteczności działania, na co wpływa silna adsorpcja cząsteczek herbicydu przez glebę.

W sezonie 2014 stwierdzono również wyższą fitotoksyczność niektórych herbicydów doglebowych względem roślin soi w stosunku do lat 2015 i 2016. Selektywność niektórych preparatów doglebowych polega na tym, że pozostają one na powierzchni gleby lub przemieszczają się względnie płytko, dzięki czemu korzenie roślin uprawnych unikają kontaktu z herbicydem (Praczyk i Skrzypczak 2004). Wystąpienie wyższych opadów w roku 2014 mogło spowodować przemieszczenie się części preparatów w glebie do strefy korzeniowej roślin soi, co spowodowało ich uszkodzenie przez niektóre herbicydy.

\section{Wnioski / Conclusions}

1. Linuron + chlomazon, linuron + S-metolachlor oraz flufenacet + metrybuzyna wykazały najwyższą skuteczność działania podczas sprzyjających warunków atmosferycznych.

2. Bardzo niska skuteczność chwastobójcza zastosowanych preparatów doglebowych w sezonie 2015 w porównaniu do sezonów 2014 i 2016 spowodowana była mniejszą ilością opadów w kwietniu. Susza w większym stopniu przyczyniła się do zmniejszenia skuteczności zwalczania chwastnicy jednostronnej niż komosy białej.

3. W sezonie 2014 o dużej ilości opadów pendimetalina oraz mieszanina pendimetaliny i chlomazonu powodowały uszkodzenia soi konwencjonalnej odmiany Augusta, które utrzymywały się do końca sezonu wegetacyjnego.

\section{Podziękowanie / Acknowledgements}

Badania wykonano w ramach grantu finansowanego przez Narodowe Centrum Badań i Rozwoju pt. „Unowocześnienie technologii uprawy konwencjonalnych odmian soi (Glycine max) w warunkach Polski”. Projekt realizowany w ramach Programu Badań Stosowanych: PBS2/A8/25/2013.

\section{Literatura / References}

Bujak K., Frant M. 2009. Wpływ mieszanek herbicydów na plonowanie i zachwaszczenie pięciu odmian soi. Acta Agrophysica 13 (3): 601-613.

Hamill A.S., Zhang J., Swanton C.J. 1994. Reducing herbicide use for weed control in soybean (Glycine max) grown in two soil types in southwestern Ontario. Canadian Journal of Plant Science 75 (1): 283-292.

Jędruszczak M., Bujak K., Wesołowski M. 2010. Chwasty w łanie soi uprawianej w siewie bezpośrednim z zastosowaniem mulczu z żyta ozimego oraz zmniejszonych dawek herbicydu. [Weeds in soybean canopy cultivated under direct sowing with winter rye mulch and reduced herbicide doses]. Annales Universitatis Mariae Curie-Skłodowska, Sectio E, Agricultura 65 (2): $29-37$.

Kapusta F. 2012. Rośliny strączkowe źródłem białka dla ludzi i zwierząt. Nauki Inżynierskie i Technologie/Engineering Sciences and Technologies 1 (4): 16-32. 
Korsak-Adamowicz M., Dopka D., Starczewski J. 2010. Oddziaływanie niektórych zabiegów agrotechnicznych na zachwaszczenie soi. [Influence of selected cultivation treatments on weed infestation in soybean]. Annales Universitatis Mariae Curie-Skłodowska, Sectio E, Agricultura 65 (4): 65-73.

Loux M.M., Doohan D., Dobbels A.F., Johnson W.G., Young B.G., Legleiter T.R., Hager A. 2015. Weed Control Guide for Ohio, Indiana and Illinois. Ohiyo - 2013, 210 pp.

Praczyk T., Skrzypczak G. 2004. Herbicydy. PWRiL, Poznań, 274 ss.

Tyczewska A., Gracz J., Twardowski T., Małyska A. 2014. Soja przyszłością polskiego rolnictwa? Nauka 4: 121-138.

Vivian R., Reis A., Kalnay P.A., Vargas L., Ferreira A.C.C., Mariani F. 2013. Weed Management in Soybean - Issues and Practices. Chapter 3. p. 47-84. DOI: 10.5772/54595. In: ”Soybean - Pest Resistance” (H.A. El-Shemy, ed.). ISBN 978-953-51-0978-5. Published: February 13, 2013 under CC BY 3.0 license.

Woźnica Z. 2008. Herbologia. Podstawy biologii, ekologii i zwalczania chwastów. PWRiL, Poznań, 430 ss.

Younesabadi M., Das T.K., Sharma A.R. 2013. Effect of tillage and tank-mix herbicide application on weed management in soybean (Glycine max). Indian Journal of Agronomy 58 (3): 372-378. 